\title{
No-Scar Transoral Thyroglossal Duct Cyst Excision in Children
}

\author{
Jin Pyeong Kim, ${ }^{1, *}$ Jung Je Park, ${ }^{1, *}$ and Seung Hoon Woo ${ }^{1-3}$
}

Background: No-scar transoral thyroglossal duct cyst (TGDC) excision is a newly developed treatment for TGDC, but limited information is available regarding the clinical outcomes in children. The aim of this study was to evaluate the safety, efficacy, and effects of transoral TGDC excision in children.

Methods: Forty-four children $<10$ years of age received operative treatment for TGDC from January 2013 to December 2014, and follow-up was performed over 24 months. Clinicopathologic, surgical, and follow-up data were collected and analyzed. The primary outcome variable was feasibility of the procedure, and the secondary outcome was patient's cosmetic satisfaction after each operation.

Results: Twenty-one patients underwent transoral TGDC excision, and 21 patients underwent conventional excision. No significant differences were observed between the two groups in terms of the overall patient and operation factors. However, the rate of identifying the thyroglossal duct during transoral excision was superior to that during conventional excision $(p<0.05)$, and cosmetic satisfaction was much better in the transoral TGDC excision group $(p<0.001)$.

Conclusion: No-scar transoral TGDC excision in children is a potentially safe and effective methodology that can achieve easy removal of the thyroglossal duct and excellent cosmetic outcomes.

Keywords: thyroglossal duct cyst, complications, scar, operation, pediatrics

\section{Introduction}

$\mathbf{T}$ HYROglossal DUCT CYSTS (TGDCs) are the most common congenital neck masses in children (1), accounting for $>70-75 \%$ of these masses (2,3). Managing TGDCs requires a detailed understanding of the anatomical development and embryogenesis of the thyroid gland $(4,5)$. The thyroid gland migrates from the tongue base to the anterior lower neck, and the remnant tract of its migration is called the thyroglossal duct (TGD) (6,7). Most TGDs are obliterated during development, but if the duct persists along the thyroid gland migration tract, it can cause retention of the epithelial tract and increase the likelihood of development of a TGDC (5). It is estimated that approximately $7 \%$ of the adult population has a TGD $(7,8)$.

The conventional TGDC operation (known as Sistrunk's operation) is the treatment of choice for symptomatic clinical TGDCs. The operation entails excision of the mid-portion of the hyoid bone with the cystic portion, as well as excision of the TGD between the foramen cecum at the tongue base and the hyoid bone to prevent cyst recurrence (9-15). Recurrence occurs in $<10 \%$ of patients who receive the conventional
TGDC operation. However, it inevitably results in a scar on the neck $(5,9,11,13-18)$. In addition, it is difficult to approach the full TGD during the traditional operation in children because the TGD is located at the tongue base and is situated far away from the transcutaneous incision site, and there is a possibility of not identifying the duct, which is very soft. Considering the external operation scar and the embryological aspects, alternative surgical approaches need to be developed that can provide access to the full TGD and leave no scar.

This study presents no-scar transoral TGDC excision with details of the operative procedures, and the postoperative clinical outcomes of no-scar transoral TGDC excision are compared with those of conventional TGDC excision in children.

\section{Methods}

This study was conducted after obtaining the approval of the Institutional Review Board, and the study was registered at the Korea Clinical Research Information Service (0000661). The guidelines of the Declaration of Helsinki were also followed.

\footnotetext{
${ }^{1}$ Department of Otolaryngology—Head and Neck Surgery, and ${ }^{2}$ Institute of Health Sciences, Gyeongsang National University, Jinju, Korea.

${ }^{3}$ Beckman Laser Institute, University of California, Irvine, California.

*These authors contributed equally to this work.

(C) Jin Pyeong Kim et al. 2018; Published by Mary Ann Liebert, Inc. This Open Access article is distributed under the terms of the Creative Commons Attribution Noncommercial License (http://creativecommons.org/licenses/by-nc/4.0/) which permits any noncommercial use, distribution, and reproduction in any medium, provided the original author(s) and the source are cited.
} 


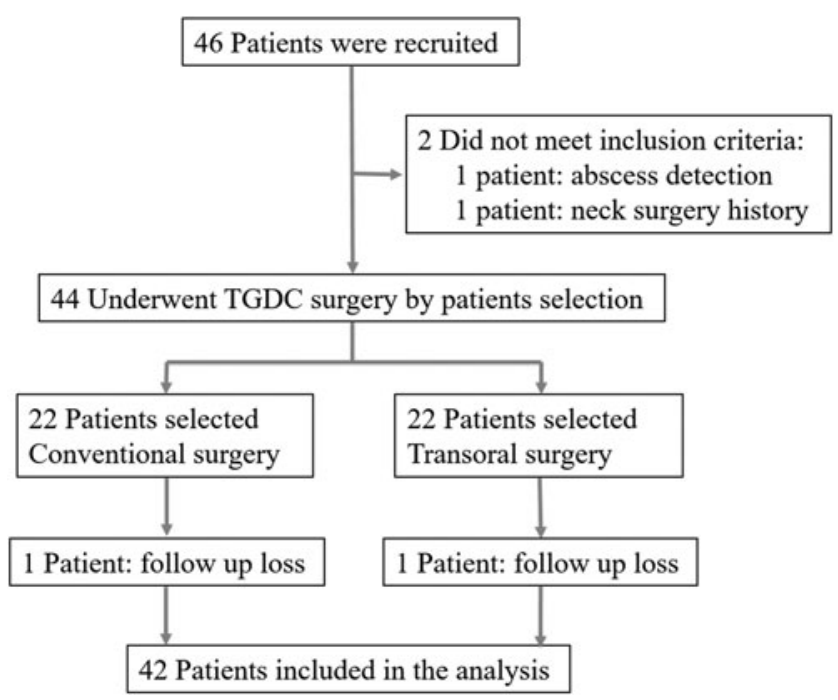

FIG. 1. Patient enrollment.

\section{Patients}

Forty-two patients $<10$ years of age who had TGDCs from January 2013 to December 2014 were registered, and the cysts were excised using either a transoral approach or a conventional transcervical approach. All patients and their parents provided informed consent after the advantages and disadvantages of each procedure and the possibility of conversion from the transoral approach to the conventional transcervical approach during the transoral procedure were explained. The patients and parents were involved in the selection of the procedure they wished to undergo (Fig. 1).

Among the initial 46 children, two did not meet the eligibility criteria, and they were excluded from the study: One had signs of an abscess on preoperative computed tomography (CT) scan and a preoperative test, and the other had a history of thyroid surgery. Two patients were also lost to follow-up, and they had received a conventional operation and a transoral operation (Fig. 1).

The inclusion criteria were diagnosis of a TGDC by physical examination, neck CT (Fig. 2A), and fine-needle aspiration biopsy. The exclusion criteria were abscess or inflammation suspected on preoperative tests or a history of head and neck malignancy or radiation therapy.

Finally, 42 children were enrolled ( 20 females; age $<10$ years; $M_{\text {age }}=7.3 \pm 2.22$ years). Either the conventional or the transoral TGDC excision was performed by a single surgeon (S.H.W., with $>10$ years' experience with this approach), following the same procedure every time. After all cysts were excised, the children received regular checkups with clinical examinations for more than two years $(M=28.97 \pm 2.63$ months) and ultrasonography twice a year.

The primary outcome variable was feasibility of the procedure, but the operation time, excision of the TGD, histopathologic outcomes, recurrence, hospital stay duration, wound problems, and complications were also assessed.

The secondary outcome variable was patient's cosmetic satisfaction after each operation, which was measured after interviewing the patients and their parents following the procedure. Specifically, the respondents gave each satisfaction parameter a score ranging from 1 to 10 (where $1=$ "extremely dissatisfied" and $10=$ "extremely satisfied"), 3 and 12 months after the surgery.
FIG. 2. (A) Computed tomography image of a thyroglossal duct cyst (TGDC). (B and $\mathbf{C}$ ) The tongue was retracted superiorly, and the incision was made in the oral mucosa above the submandibular gland opening (white arrow). (D) After the incision was made, the genioglossus muscles can be seen in the surgical field (black arrow). Color images available online at www.liebertpub.com/thy
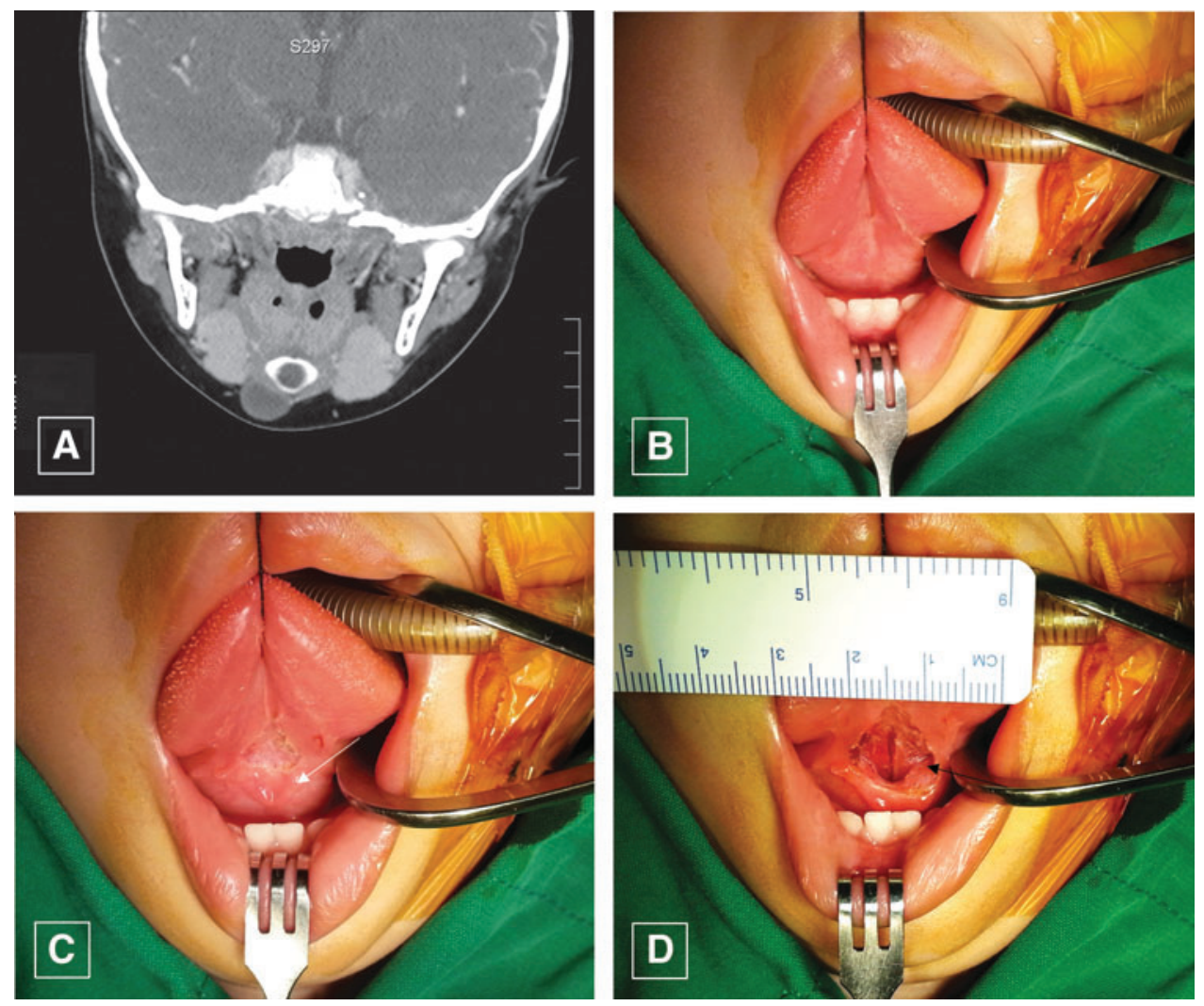


\section{Sample size}

To determine the number of study subjects needed for this study, calculation was performed with statistical power (1- $\beta$ ) of 0.85 , level of significance $(\alpha)$ of 0.05 , intermediate effect size of 0.25 , and the correlation coefficient between repeated measures $(r)$ of 0.50 on repeated measures analysis of variance using $\mathrm{G}^{*}$ Power v3.1.7. As a result, 19 subjects were required in each group. Anticipating dropouts, this study included 22 subjects in the experimental group and 22 subjects in the control group. One subject from the conventional group and one subject from the transoral group dropped out due to being lost to follow-up during the data collection period. Therefore, 21 subjects in the experimental group and 21 subjects in the control group were finally analyzed in this study.

\section{Surgical technique}

Transoral TGDC excision. Under general anesthesia, the surgeon retracted the tongue of the child superiorly after opening the mouth with a Denhart retractor (Fig. 2B), making an approximately $1 \mathrm{~cm}$ horizontal incision on the tongue's frenulum mucosa above the submandibular gland opening (Fig. 2C). After the mucosal incision, the surgeon could identify the genioglossus muscle (GM) in the operation field (Fig. 2D). Surgical dissection was performed under a magnified endoscopic view (rigid, $10 \mathrm{~mm}, 0^{\circ}$; Olympus, Tokyo, Japan). The GM is composed of two parts - a left side and a right side - and the surgeon dissected between the two parts of GM and found an avascular space in the middle. After the surgeon retracted the GMs bilaterally with Sofield retractors (Zimmer Biomet, Warsaw, IN; Fig. 3A), he identified the TGD where it originated from the foramen cecum to the hyoid bone (Fig. 3B and $\mathrm{C}$ ). The surgeon then dissected the TGD apart from the tongue muscle (Fig. 3D). Next, the surgeon cut the TGD just below the foramen cecum and the hyoid bone with an endoscopic dissector (Aesculap, Inc., Center Valley, PA) and ultrasonic scissors (Harmonic scalpel 300; Ethicon, a Johnson \& Johnson Company, Cincinnati, OH; Fig. 3E-G), after which the surgeon dissected the hyoid bone and cut it into $1 \mathrm{~cm}$ lengths using an Osteo Punch Rongeur $(1 \mathrm{~mm}$; Koros USA, Inc., Moorpark, CA). As the cutoff hyoid bone was pulled upwards, the attached TGDC was also pulled upwards (Fig. 3I), and the surgeon could carefully dissected each cyst and remove it through the oral cavity incision site (Fig. 4A). After irrigating the surgical field, the surgeon approximated the GM using 4-0 Vicryl and sutured the oral mucosa vertically (Fig. 4B). The surgeon encouraged frequent oral gargling $(0.02 \%$ chlorhexidine) and prescribed antibiotics for three days, and oral feeding with a normal diet was allowed after one day.

Conventional TGDC excision. To excise each TGDC, the surgeon made an approximately $5 \mathrm{~cm}$ horizontal skin incision in the hyoid region and created a flap that extended $1 \mathrm{~cm}$ above the hyoid bone and $1 \mathrm{~cm}$ inferior to the TGDC. After the surgeon divided the median raphe of the strap muscles, the dissection proceeded superior to the hyoid bone. After that, the surgeon dissected and cut the hyoid bone into fragments of $1 \mathrm{~cm}$ in length using bone-cutting forceps. The surgeon performed careful dissection of the TGD, extending from the resected hyoid bone to the tongue base, from the attached tissues. After that, the surgeon sutured each subcutaneous layer and skin.

\section{Statistical analysis}

The statistical data were compared between the two groups using independent-sample $t$-tests and Fisher's exact test with SPSS for Windows v12.0 (SPSS, Inc., Chicago, IL), and a $p$-value of $<0.05$ was considered statistically significant.

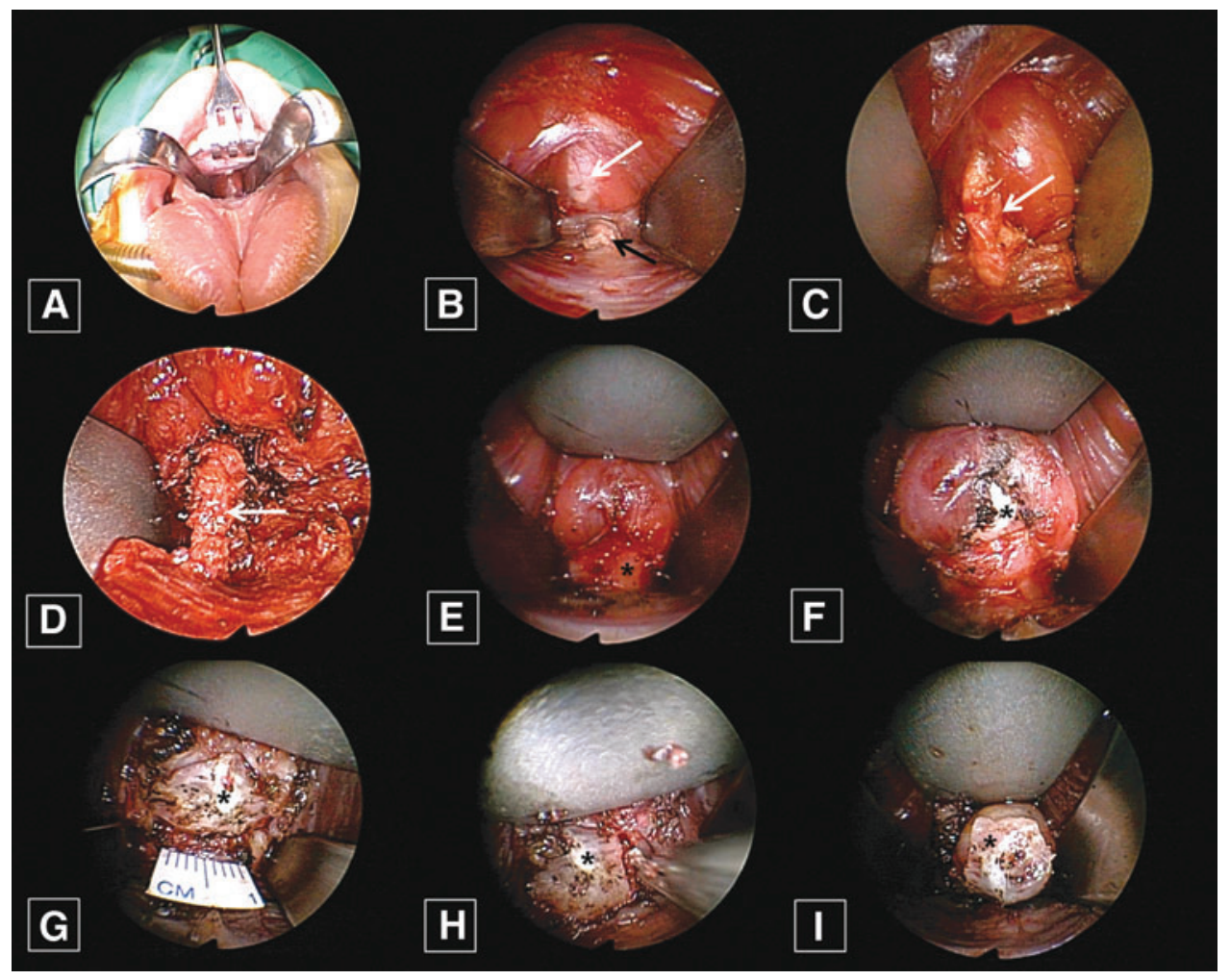

FIG. 3. (A) The genioglossus muscles were separated at the midline and retracted bilaterally. (B and C) After retraction of the muscles, the thyroglossal duct (TGD; white arrow) could be identified at the foramen cecum (black arrow). (D) The TGD (white arrow) was then dissected from the mid-portion of the tongue muscle. (E-G) Next, the TGD was cut, and the hyoid bone was identified (asterisk). (H) After that, the hyoid bone (asterisk) was cut into fragments that were $1 \mathrm{~cm}$ length. (I) The cyst was attached to the cut hyoid bone (asterisk) and then pulled upward. Color images available online at www.liebertpub .com/thy 
FIG. 4. (A) The surgical specimen shows the TGD (white arrow), the hyoid bone (asterisk), and the cyst. (B) After removal of the TGDC, the genioglossus muscles and the oral mucosa were sutured. (C and D) The transoral TGDC excision wound healed well (C: 1 week; D: 3 month later). Color images available online at www.liebertpub.com/thy
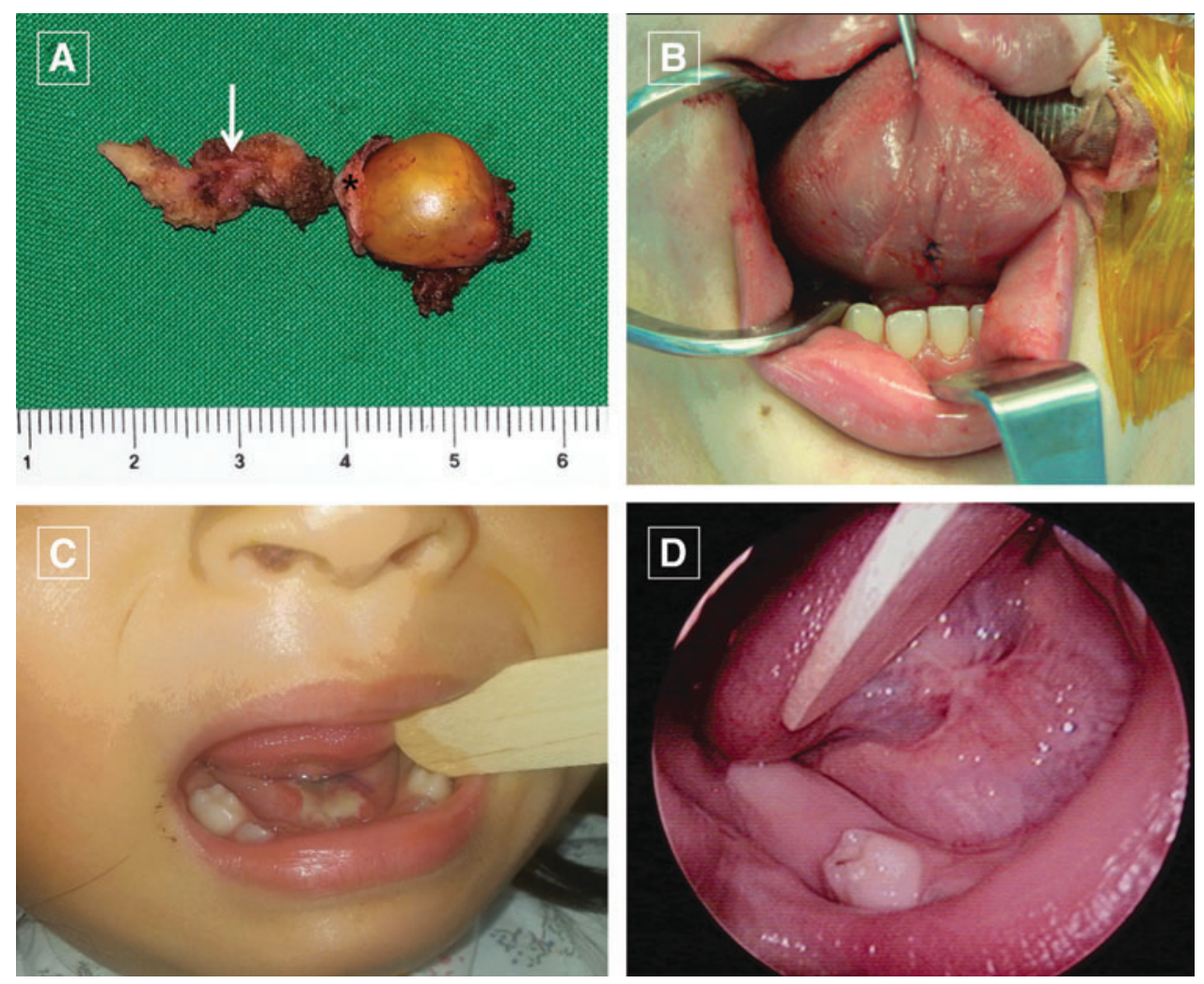

\section{Results}

\section{Patient characteristics}

Twenty-one patients underwent the transoral approach, and the other 21 patients underwent the conventional approach, with each TGDC being successfully excised either transorally or conventionally. None of the transoral approaches had to be converted to the transcervical approach. The patients' clinical data and results are shown in Table 1.

In the transoral group, there were 10 females and 11 males, with an average age of $8.4 \pm 2.5$ years. In this group, there were 14 cases with neck mass symptoms and seven cases of neck swelling. The mean length of the oral mucosal incision was $1.2 \pm 0.62 \mathrm{~cm}$ (range $1.0-1.5 \mathrm{~cm}$ ). The median cyst size was $21.65 \pm 17.22 \mathrm{~mm}$. The average operating time was $67.3 \pm 17.3 \mathrm{~min}$ (range 60-90 $\mathrm{min}$ ). The average hospital stay was $3.4 \pm 0.56$ days, and blood loss was minimal.

In the conventional group, there were 10 females and 11 males, with an average age of $8.7 \pm 3.2$ years. In this group, there were 15 cases with neck mass symptoms, four cases of neck swelling, and one case of neck hyperemia and dysphagia each. The mean length of the skin incision was $5.6 \pm 2.4 \mathrm{~cm}$ (range $5.0-7.5 \mathrm{~cm}$ ). The median cyst size was $20.3 \pm 11.7 \mathrm{~mm}$. The average operating time was $65.0 \pm 30.1 \mathrm{~min}$ (range 60$100 \mathrm{~min}$ ). The average hospital stay was $4.2 \pm 2.6$ days, and blood loss was minimal.

\section{Clinical outcomes}

Although there were no significant differences between the two groups in terms of age, sex, cyst size, hospital stay length, and pathology results, the operation times were longer with the transoral approach than with the conventional ap- proach $(p<0.05)$. All children received a follow-up every six months after each operation for at least 24 months.

Complete removal of TGDs is very important in TGDC operations. In the transoral group, the duct could be easily identified at the midline of the avascular space between the genioglossus muscles, and it was easy to identify the shape and direction of the duct, as it originated from the foramen cecum and ran forward toward the hyoid bone. The duct was identified in $17(81 \%)$ cases in the transoral group and in 14 $(67 \%)$ cases in the conventional group, and the difference was significant $(p=0.04)$

In both the transoral and conventional groups, the cysts were successfully removed in all cases, and the pathology results indicated that all of the cysts were TGDCs. However, one child in the conventional group developed temporary hypoglossal nerve paralysis. This child's tongue was deviated to the left side when it was pushed. However, it recovered within four weeks after the operation. Additionally, each group had one child who developed a seroma after the operation, but in each case, the seroma disappeared within two weeks. There was also no infection after any of the operations in either group.

During more than two years of follow-up, one case of recurrence was observed in the conventional group after 13 months of surgery. However, the cyst was $<1 \mathrm{~cm}$, and the patient did not want to undergo surgery again. Thus, only a follow-up could be performed.

The transoral operation wound in the oral cavity healed well in all cases (Fig. 4C and D). Following the conventional operation, a scar persisted at the place of the incision (Supplementary Fig. S1; Supplementary Data are available online at www.liebertpub.com/thy). Separately, the mean satisfaction scores in the transoral group were $9.33 \pm 0.85$ after three 
Table 1. Comparison of Characteristics and Postoperative Results Between the Transoral and Conventional Groups

\begin{tabular}{|c|c|c|c|c|c|}
\hline & \multicolumn{2}{|c|}{ Transoral group $(\mathrm{n}=21)$} & \multicolumn{2}{|c|}{ Conventional group $(\mathrm{n}=21)$} & p-Value \\
\hline Age (years) & \multicolumn{2}{|c|}{$8.04 \pm 1.07$} & \multicolumn{2}{|c|}{$8.33 \pm 0.85$} & 0.30 \\
\hline Sex (male:female) & \multicolumn{2}{|c|}{$11: 10$} & \multicolumn{2}{|c|}{$11: 10$} & 1.00 \\
\hline Preoperative symptom (cases) & \multirow{2}{*}{\multicolumn{2}{|c|}{14}} & \multirow{2}{*}{\multicolumn{2}{|c|}{15}} & \\
\hline Neck mass & & & & & \\
\hline Neck swelling & \multicolumn{2}{|c|}{7} & \multicolumn{2}{|c|}{4} & \\
\hline Neck infection & \multirow{2}{*}{\multicolumn{2}{|c|}{$\begin{array}{l}0 \\
0\end{array}$}} & \multicolumn{2}{|c|}{1} & \\
\hline Dysphagia & & & \multicolumn{2}{|c|}{1} & \\
\hline Thyroglossal duct finding & \multicolumn{2}{|c|}{$17(81 \%)$} & \multicolumn{2}{|c|}{$14(67 \%)$} & 0.04 \\
\hline Operation time (min) & \multicolumn{2}{|c|}{$66.80+8.70$} & \multicolumn{2}{|c|}{$71.42 \pm 13.88$} & 0.02 \\
\hline Length of hospitalization (days) & \multicolumn{2}{|c|}{$4.33 \pm 0.57$} & \multicolumn{2}{|c|}{$4.71 \pm 0.64$} & 0.08 \\
\hline Follow-up (months) & \multicolumn{2}{|c|}{$28.04 \pm 2.08$} & \multirow{2}{*}{\multicolumn{2}{|c|}{$\begin{array}{l}29.04 \pm 2.22 \\
20.90 \pm 4.30\end{array}$}} & 0.07 \\
\hline Size of TGDC (mm) & \multicolumn{2}{|c|}{$21.85 \pm 3.49$} & \multirow{2}{*}{\multicolumn{2}{|c|}{$5.6 \pm 2.4$ (skin) }} & 0.35 \\
\hline Incision length $(\mathrm{cm})$ & \multicolumn{2}{|c|}{$1.2 \pm 0.62$ (oral) } & & & \\
\hline Complications (case) & \multirow{2}{*}{\multicolumn{2}{|c|}{0}} & \multirow{2}{*}{\multicolumn{2}{|c|}{1}} & \\
\hline Recurrence & & & & & \\
\hline Seroma & \multirow{2}{*}{\multicolumn{2}{|c|}{1}} & \multicolumn{2}{|c|}{1} & \\
\hline Nerve injury & & 0 & \multicolumn{2}{|c|}{1} & \\
\hline Subjective cosmetic results & 3 months & 12 months & 3 months & 12 months & \\
\hline $9-10=$ extremely satisfied & 18 & 19 & 0 & 1 & \\
\hline $7-8=$ satisfied & 3 & 2 & 9 & 9 & \\
\hline $5-6=$ average & 0 & 0 & 5 & 8 & \\
\hline $3-4=$ dissatisfied & 0 & 0 & 4 & 2 & \\
\hline $1-2=$ extremely dissatisfied & 0 & 0 & 3 & 1 & \\
\hline Cosmetic result mean & $9.33 \pm 0.85$ & $9.42 \pm 0.67$ & $5.38 \pm 2.22$ & $6.19 \pm 1.86$ & 0.001 \\
\hline
\end{tabular}

TGDC, thyroglossal duct cyst.

months and $9.42 \pm 0.67$ after 12 months. In the conventional group, the mean satisfaction scores were $5.38 \pm 2.22$ after three months and $6.19 \pm 1.86$ after 12 months. This difference was significant $(p=0.001)$.

\section{Discussion}

Surgical excision is widely accepted as a definitive treatment for TGDCs. Recurrence rates vary in the literature, and they have been reported to be as low as $0-12.2 \%$ after employing either the classic or modified Sistrunk procedure $(12,19,20)$, and approximately $40 \%$ after simple cyst excision $(14,21)$. Hyoid resection was performed significantly less frequently during surgery for recurrent disease, and this may explain the rationale for deviation from the standard approach (21).

Currently, TGDCs are most commonly treated using a transcervical approach. The concept of this technique is to remove the cyst, the middle of the hyoid bone, and the TGD from the foramen cecum to the hyoid bone $(5,9,12,15-18,22)$. This procedure reduced the recurrence rates and improved the TGDC excision surgical results, and it remains the gold standard for surgical management of TGDCs $(4,14,23,24)$.

Understanding the embryogenesis and histopathology of the thyroid is necessary for successful treatment of TGDCs (25). In accordance with the embryological development of the TGDC from the foramen cecum to the hyoid bone, the chosen approach allows the TGDCs to be excised transorally $(26,27)$. Following this naturally predetermined access alongside each cyst, it was possible to develop a new surgical approach to the anterior neck area $(10,27)$.

With the transoral approach presented here, the surgeon can easily identify the TGD, the hyoid bone, and the TGDCs, and in particular, the surgeon can easily locate the ducts originating from the foramen cecum to the hyoid bone between this natural dehiscence. In this study, the surgeon identified the ducts in $81 \%$ of cases in the transoral group, but the ducts were identified in only $67 \%$ of the cases in the conventional group. This result could have been obtained because pediatric TGDs are thin, and sometimes it is difficult to access them fully through conventional surgery because of small skin incisions or operation fields. In addition, TGDs can be easily cut, and there can be intraoperative loss of TGD components because these ducts are very soft in children. This can be problematic because remnant TGD tissue can increase the chances of TGDC recurrence. In this study, TGDs could not be identified in $19 \%$ of the pediatric patients. Initially, it was expected that it would be possible to identify TGDs in all pediatric patients because it was thought that the TGD would disappear in adulthood. However, the TGD seemed to disappear earlier than expected.

Transoral TGDC excision has the advantage of identifying TGDs. Use of this approach allowed the full TGD to be visualized from the tongue base to the hyoid bone because the duct is located immediately between the genioglossus muscles. The surgeon can just retract the genioglossus muscle bilaterally and thereby easily identify the duct. This anatomical structure offers clear guidance and facilitates the transoral access to TGDCs.

Transoral TGDC excision is essentially the same as the conventional cyst excision. The only difference is in the approach. After incision of the oral mucosa and retraction of the genioglossus muscle bilaterally, the surgeon can identify the hyoid bone and dissect the strap muscles from the bone. After identification of the hyoid bone, the middle portion is 
cut and removed, together with the TGDC, through careful dissection. This procedure was concordant with the conventional TGDC excision approach $(9,11,12,14,15)$. In a previous study, it was found that the outcomes after transoral TGDC excision in adults are very good: 29 (97\%) patients achieved preoperative oral function within one month, and no postoperative problems were found (especially in terms of scarring in the floor of the mouth and lingual sensation) because the transoral approach is not complicated and has the advantage of minimizing access trauma $(2,25,28-35)$.

In children, the hyoid bone is higher than it is in adults. Therefore, the surgeon can very easily identify the cysts, which are located only $3 \mathrm{~cm}$ from the oral mucosal incision, using the transoral approach during pediatric TGDC operations. In addition, because the hyoid bone in pediatric patients is not yet ossified, the hyoid bone can be cut very easily. These two aspects facilitate the excision of TGDCs in children in comparison to adults.

The transoral approach has been a good option for treating TGDCs in children, but this approach has only recently been introduced, and complications have not been fully investigated. In this study, minor complications such as seromas occurred in each group, but they disappeared quickly. In particular, the conventional group had one case of temporary hypoglossal nerve paralysis and one case of TGDC recurrence. Nerve paralysis could have been caused by retraction of the surgical specimen, and recurrence could have been due to a remnant of the TGD in the operation field. However, nerve paralysis completely resolved within four weeks, and the recurrent cyst did not grow. Therefore, the patient only required clinical follow-up.

This study has some limitations. First, although the patients were followed for two years, in order to evaluate the risks and benefits of the described procedure, a longer followup may be needed. Second, additional studies with larger sample sizes may be needed to investigate the differences among various age and sex groups. It may also be necessary to improve the reliability and applicability of the data for treating and managing patients who have undergone transoral TGDC excision.

In conclusion, transoral TGDC excision is a potentially safe and effective methodology that leads to good cosmetic outcomes. Additionally, considering the embryological development of TGDCs, the transoral approach forms a logical access route to these cysts.

\section{Acknowledgments}

This research was supported by the Basic Science Research Program through the National Research Foundation of Korea funded by the Ministry of Science, ICT, and Future Planning (2016R1A2B4013000). The research was also supported by the Leading Foreign Research Institute Recruitment Program through the National Research Foundation of Korea funded by the Ministry of Education, Science and Technology (2012K1A4A3053142).

\section{Author Disclosure Statement}

No financial or material support has been received for this work. Moreover, the authors declare no financial interests in companies or other entities that could have an interest in the information within this contribution. None of the authors have any conflicts of interest, financial or otherwise.

\section{References}

1. Radkowski D, Arnold J, Healy GB, McGill T, Treves ST, Paltiel H, Friedman EM 1991 Thyroglossal duct remnants. Preoperative evaluation and management. Arch Otolaryngol Head Neck Surg 117:1378-1381.

2. Allard RH 1982 The thyroglossal cyst. Head Neck Surg 5: 134-146.

3. Sammarco GJ, Mc Kenna J 1970 Thyroglossal duct cysts in the elderly. Geriatrics 25:98-101.

4. Hussain K, Henney S, Tzifa K 2013 A ten-year experience of thyroglossal duct cyst surgery in children. Eur Arch Otorhinolaryngol 270:2959-2961.

5. Marianowski R, Ait Amer JL, Morisseau-Durand MP, Manach Y, Rassi S 2003 Risk factors for thyroglossal duct remnants after Sistrunk procedure in a pediatric population. Int J Pediatr Otorhinolaryngol 67:19-23.

6. Moore KL PT 1993 The Developing Human. Clinically Oriented Embryology. Fifth edition. Saunders, Philadelphia, PA.

7. Ewing CA, Kornblut A, Greeley C, Manz H 1999 Presentations of thyroglossal duct cysts in adults. Eur Arch Otorhinolaryngol 256:136-138.

8. Hilger AW, Thompson SD, Smallman LA, Watkinson JC 1995 Papillary carcinoma arising in a thyroglossal duct cyst: a case report and literature review. J Laryngol Otol 109:1124-1127.

9. Hirshoren N, Neuman T, Udassin R, Elidan J, Weinberger JM 2009 The imperative of the Sistrunk operation: review of 160 thyroglossal tract remnant operations. Otolaryngol Head Neck Surg 140:338-342.

10. Lin ST, Tseng FY, Hsu CJ, Yeh TH, Chen YS 2008 Thyroglossal duct cyst: a comparison between children and adults. Am J Otolaryngol 29:83-87.

11. Maddalozzo J, Venkatesan TK, Gupta P 2001 Complications associated with the Sistrunk procedure. Laryngoscope 111:119-123.

12. Mondin V, Ferlito A, Muzzi E, Silver CE, Fagan JJ, Devaney KO, Rinaldo A 2008 Thyroglossal duct cyst: personal experience and literature review. Auris Nasus Larynx 35:11-25.

13. Perkins JA, Inglis AF, Sie KC, Manning SC 2006 Recurrent thyroglossal duct cysts: a 23-year experience and a new method for management. Ann Otol Rhinol Laryngol 115: 850-856.

14. Shah R, Gow K, Sobol SE 2007 Outcome of thyroglossal duct cyst excision is independent of presenting age or symptomatology. Int J Pediatr Otorhinolaryngol 71:1731-1735.

15. Khurana KK, Richards VI, Chopra PS, Izquierdo R, Rubens D, Mesonero C 1998 The role of ultrasonography-guided fine-needle aspiration biopsy in the management of nonpalpable and palpable thyroid nodules. Thyroid 8:511-515.

16. Brousseau VJ, Solares CA, Xu M, Krakovitz P, Koltai PJ 2003 Thyroglossal duct cysts: presentation and management in children versus adults. Int $\mathrm{J}$ Pediatr Otorhinolaryngol 67:1285-1290.

17. Kaselas C, Tsikopoulos G, Chortis C, Kaselas B 2005 Thyroglossal duct cyst's inflammation. When do we operate? Pediatr Surg Int 21:991-993.

18. Ostlie DJ, Burjonrappa SC, Snyder CL, Watts J, Murphy JP, Gittes GK, Andrews WA, Sharp RJ, Holcomb GW 3rd 2004 Thyroglossal duct infections and surgical outcomes. J Pediatr Surg 39:396-399; discussion 396-399.

19. Geller KA, Cohen D, Koempel JA 2014 Thyroglossal duct cyst and sinuses: a 20-year Los Angeles experience and lessons learned. Int J Pediatr Otorhinolaryngol 78:264-267. 
20. Sistrunk WE 1920 The surgical treatment of cysts of the thyroglossal tract. Ann Surg 71:121-122.

21. Ross J, Manteghi A, Rethy K, Ding J, Chennupati SK 2017 Thyroglossal duct cyst surgery: a ten-year single institution experience. Int J Pediatr Otorhinolaryngol 101:132-136.

22. Nicollas R, Mimouni O, Roman S, Triglia JM 2007 Intralaryngeal manifestation of thyroglossal duct cyst. Otolaryngol Head Neck Surg 137:360-361.

23. Chou J, Walters A, Hage R, Zurada A, Michalak M, Tubbs RS, Loukas M 2013 Thyroglossal duct cysts: anatomy, embryology and treatment. Surg Radiol Anat 35:875-881.

24. Sistrunk WE 1920 The surgical treatment of cysts of the thyroglossal tract. Ann Surg 122:121-122.

25. Kim JP, Park JJ, Lee EJ, Woo SH 2011 Intraoral removal of a thyroglossal duct cyst using a frenotomy incision. Thyroid 21:1381-1384.

26. Karakas E, Steinfeldt T, Gockel A, Schlosshauer T, Dietz C, Jager J, Westermann R, Sommer F, Richard HR, Exner C, Sesterhenn AM, Bartsch DK Transoral thyroid and parathyroid surgery-development of a new transoral technique. Surgery 150:108-115.

27. Karakas E, Steinfeldt T, Gockel A, Westermann R, Kiefer A, Bartsch DK Transoral thyroid and parathyroid surgery. Surg Endosc 24:1261-1267.

28. Woo SH, Kim JP, Baek CH 2016 Endoscope-assisted extracapsular dissection of benign parotid tumors using hairline incision. Head Neck 38:375-379.

29. Woo SH 2014 Endoscope-assisted transoral thyroidectomy using a frenotomy incision. J Laparoendosc Adv Surg Tech A 24:345-349.
30. Woo SH 2013 Endoscope-assisted intraoral removal of the thyroid isthmus mass using a frenotomy incision. J Laparoendosc Adv Surg Tech A 23:787-790.

31. Kim JP, Park JJ, Jeon SY, Ahn SK, Hur DG, Kim DW, Park HW, Woo SH 2012 Endoscope-assisted intraoral resection of external dermoid cyst. Head Neck 34:907-910.

32. Woo SH 2016 Endoscope-assisted transoral accessory parotid mass excision. Head Neck 38:E7-E12.

33. Woo SH, Jeong HS, Kim JP, Park JJ, Baek CH 2013 Endoscope-assisted intraoral removal of ectopic thyroid tissue using a frenotomy incision. Thyroid 23:605-608.

34. Woo SH, Jeong HS, Kim JP, Park JJ, Baek CH 2014 Endoscope-assisted frenotomy approach to median upper neck masses: clinical outcomes and safety (from a Phase II clinical trial). Head Neck 36:985-991.

35. Woo SH, Park JJ, Hong JC, Wang SG, Park GC, Eun YG, Kim JP, Jeong HS 2015 Endoscope-assisted transoral removal of a thyroglossal duct cyst using a frenotomy incision: a prospective clinical trial. Laryngoscope 125:2730-2735.

Address correspondence to: Seung Hoon Woo, MD Department of OtorhinolaryngologyHead and Neck Surgery

Gyeongsang National University Hospital

90 Chilam-dong

Jinju 660-702

South Korea

E-mail: lesaby@hanmail.net 